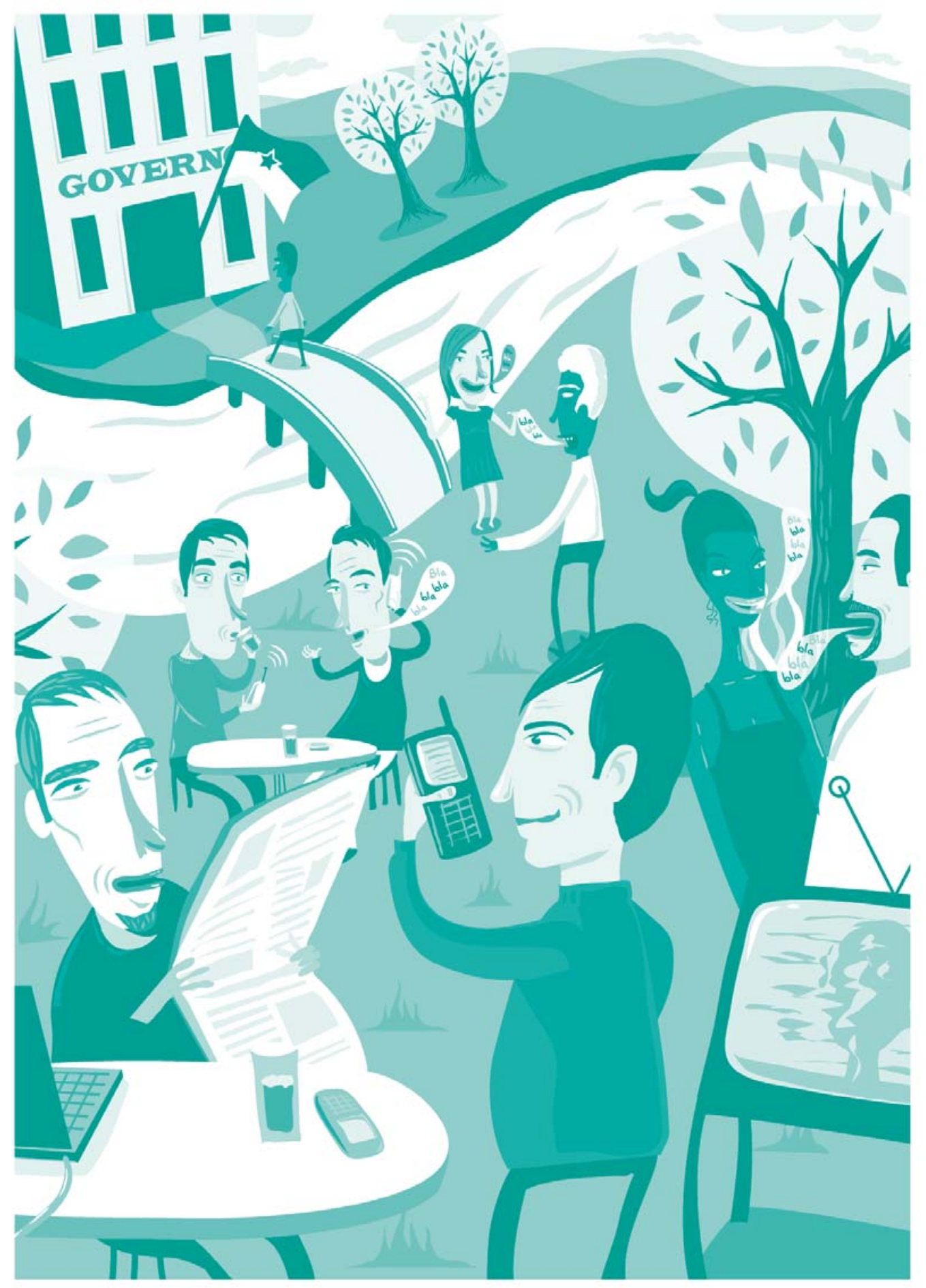




\section{Cibercidadania: a virtualização na Comunicação Pública contemporânea}

José Augusto Pereira Brito

- Doutor em Ciências da Comunicação pela Escola de Comunicações e Artes da Universidade de São Paulo (ECA-USP)

- Mestre em Engenharia Civil pela Pontifícia Universidade Católica do Rio de Janeiro (PUC-RJ)

- Especialista em Engenharia de Sistemas e Computação pela Universidade Federal do Rio de Janeiro (COPPE-UFRJ)

- Pós-graduado em Administração de Empresas pela Fundação Getúlio Vargas (FGV-SP)

- Pesquisador da Pós-Graduação da Universidade Presbiteriana Mackenzie São Paulo

- Engenheiro, professor universitário e conferencista

- Gerente-geral de Tecnologia da Informação do Instituto Presbiteriano Mackenzie - São Paulo

-brito@mackenzie.br 


\section{Resumo}

As transformações na Comunicação Pública contemporânea são analisadas considerando o papel social do governo na inclusão informacional e a cidadania na democracia por meio da tecnologia e do e-governo. Neste sentido, a informação digital; os serviços on-line; a ética no ambiente virtual; e a comunicação interativa em rede são os suportes da sociedade e das organizações.

PALAVRAS-CHAVE: COMUNICAÇÃO PÚBLICA - E-GOVERNO • E-DEMOCRACIA • CIDADANIA

\section{Abstract}

Transformations on the current Public Communication are analyzed in view of the government social function for the informational inclusion, the citizenship in democracy by the technology, and the e-government, having the digital information, the on-line services, ethics in the virtual environment, and the network interactive communication as the society and organizations support.

KEYWORDS: PUBLIC COMMUNICATION • E-GOVERNMENT • E-DEMOCRACY • CITIZENSHIP

\section{Resumen}

Transformaciones en la Comunicación Pública contemporánea son analizadas considerando el papel social del gobierno para la inclusión informacional, la ciudadanía en la democracia impregnada por la nueva tecnología y por el e-gobierno, en el cual los suportes de la sociedad y de las organizaciones son la información digital, los servicios on-line, la ética en el ambiente virtual y la comunicación interactiva por la red.

PALABRAS CLAVES: COMUNICACIÓN PÚBLICA - E-GOBIERNO - E-DEMOCRACIA - CIUdAdANÍA 
$\mathrm{E}$ ste artigo visa a contribuir para a análise da Comunicação Pública, tendo como foco a inserção crescente das Tecnologias de Informação e Comunicação (TICs) nos processos comunicacionais, com desdobramentos para o cidadão, a sociedade e a democracia.

Ao passo que os fenômenos dos media de massa e da Comunicação Política têm sido tratados por vários autores brasileiros, entre eles, Torquato (2002), Gomes (2004) e Matos (2003), os estudos sobre os novos media estão sendo gradativamente assumidos por uma parcela crescente de autores, como Lévy (2002), Castells (2000), Eisenberg (2002) e Brito (2005), com propostas para vencer grandes desafios públicos e sociais. Antônio Rubim traduz esta visão, quando incentiva a investigação científica das relações comunicacionais virtuais, objeto deste trabalho:

"O desenvolvimento acelerado da comunicação midiática, em meio a esse mutante contexto socioeconômico, produziu certamente um vigoroso impacto societário, estimulando seu estudo com relação às diferenciadas esferas sociais, com destaque para a economia, a educação, a cultura e a política". (RUBIM, 2000, p. 13)

O Brasil já é uma referência global na adoção das TICs nos serviços on-line de governo. No entanto, sob a ótica dos fundamentos da democracia e do relacionamento governo-cidadão, o país ainda é considerado como emergente na inclusão digital, com uma revolução ainda por acontecer, segundo afirma Chahin em e-Gov.br, a próxima revolução brasileira (CHAHIN, 2004).

\section{Inclusão informacional: requisito essencial na relação governo-cidadão}

O desenvolvimento de um plano estratégico abrangente de infra-estrutura de informação no Brasil (lançado em 1999) foi finalizado em setembro de 2000, quando o Ministério da Ciência e Tecnologia concebeu o Programa Sociedade da Informação (Socinfo) como parte do Plano Plurianual 2000-2004, visando a um novo estágio de evolução da Internet e suas aplicações no país. A versão portuguesa do Socinfo, que inspirou o governo brasileiro, assim conceitua a Sociedade de Informação, numa linguagem simples e objetiva:

"A expressão 'sociedade de informação' refere-se a um modo de desenvolvimento social e econômico em que a aquisição, armazenamento, processamento, valorização, trans- 
missão, distribuição e disseminação de informação pertinente à criação de conhecimento e à satisfação das necessidades dos cidadãos e das empresas, desempenham um papel central na atividade econômica, na criação de riqueza, na definição da qualidade de vida dos cidadãos e das suas práticas culturais.

A sociedade de informação corresponde, por conseguinte, a uma sociedade cujo funcionamento recorre crescentemente a redes digitais de informação. Esta alteração do dominio da atividade econômica e dos fatores determinantes de bem-estar social é resultante do desenvolvimento das novas tecnologias de informação, do audiovisual e das comunicações, com as suas importantes ramificações e impactos no trabalho, na educação, na ciência, na saúde, no lazer, nos transportes e no ambiente, entre outras". (Ministério da Ciência e Tecnologia, 1997)

O programa Socinfo brasileiro incluiu oito linhas de ação principais dos governos federal, estaduais e municipais, juntamente com a iniciativa privada e o terceiro setor. O programa previu a capacitação de pessoal para pesquisa e desenvolvimento e a garantia de serviços avançados de comunicação e informação, com áreas de atuação priorizando a ciência, a tecnologia, a educação e a cultura (TAKAHASHI, 2000).

Importante papel do governo na sociedade informacional é a sua participação na criação e fortalecimento de regras básicas, regulamentações e infra-estrutura adequada para os cidadãos e organizações. Parte dessa função vem sendo viabilizada de forma crescente por organismos independentes, sociedades anônimas, de economia mista e organizações não-governamentais nacionais ou internacionais. Na era da informação, os governos demonstram ter plena consciência de que o futuro será condicionado pela forma como as novas tecnologias de informação e comunicação serão assimiladas, assim como pelo êxito e rapidez dessa absorção ${ }^{1}$. Quanto maior a visão de que a informação, o conhecimento e seu uso apropriado serão as fontes de controle e riquezas na economia digital, mais o acesso à tecnologia da informação torna-se crucial e necessário.

A velocidade da inovação tecnológica - em tempo real - é de complexa absorção pelos cidadãos e organizações (LOCKE, 2000). No contexto global, lamentavelmente, o Brasil não tem tido avanços tão substanciais. O resultado é um abismo que segrega significativa legião de analfabetos digitais - cerca de $87 \%$ da população, de acordo com o IBOPE/ NetRatings ${ }^{2}$. A figura 1, a seguir, destaca o baixo percentual de microcomputadores existentes nos domicílios brasileiros.

10 projeto "i2010 - A European Information Society for Growth and Employment", da União Européia, por exemplo. Disponível em: < http://europa.eu.int/information_society/ eeurope/i2010/index_en.htm>. Acesso em: 05 jun. 2006.

2 Cf. Comitê Gestor da Internet no Brasil. Disponível em: <http://www.cgi.br/infoteca/clipping/2006/midia50.htm>. Acesso em: 05 jun. 2006. 
Figura 1. Percentual de domicílios no Brasil - sobre o total da população - que possuem equipamentos TIC 3

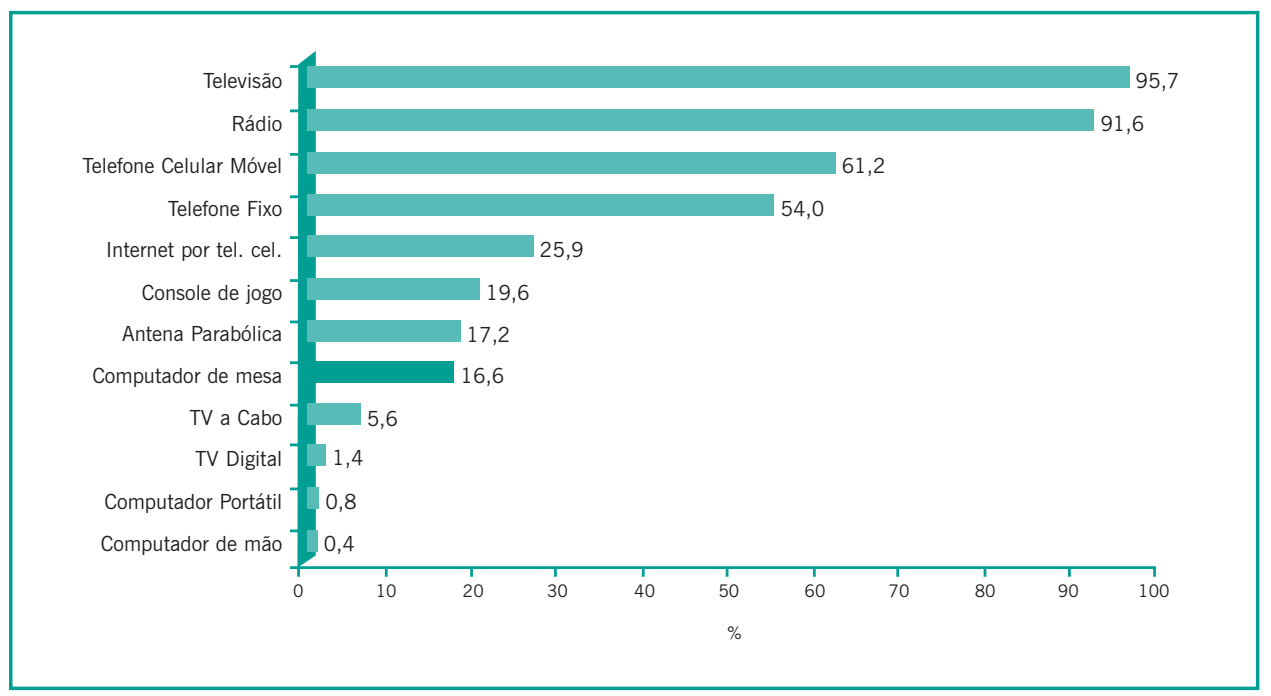

A info-inclusão é uma das principais questões da sociedade da informação, com maiores agravantes nos países em desenvolvimento, como é o caso do Brasil (GENTILI, 1999; SILVEIRA, 2001). A garantia da igualdade de acesso aos novos media é a principal providência a ser tomada para a minimização do problema. Nessa direção, as ações do governo e das parcerias público-privadas (PPPs) são absolutamente necessárias à disponibilização do acesso às novas tecnologias de informação e comunicação, permeando toda a sociedade com ampla cobertura da infra-estrutura necessária. Os espaços públicos e comunitários são estratégicos para tal iniciativa, incluindo as escolas, bibliotecas, igrejas, postos dos correios e convênios com instituições privadas, como as agências bancárias e escolas particulares. Além da cobertura geográfica, todas as faixas etárias e sociais precisam ser contempladas. Estar on-line deixa de ser um privilégio na sociedade contemporânea para se tornar um direito, à semelhança das áreas da saúde e da educação.

A figura 2 ilustra o atraso do Brasil no campo da inclusão digital. O "Índice de Acesso Digital do Brasil” está na $15^{\text {a }}$ posição no continente americano, segundo métrica da International Communication Union (ITU), vinculada à ONU, atrás de países como

3 Base: 8.540 domicílios entrevistados. Respostas múltiplas (pesquisa de ago-set/2005 - Instituto IPSOS). Fonte: CGI.br. Disponível em: <http://www.nic.br/indicadores/usuarios/rel-geral-01.htm>. Acesso em: 27 mai. 2006. 
México, Argentina, Uruguai e Chile ${ }^{4}$. Dados do Ibope/NetRatings de março de 2006 mostram que cerca de 14,1 milhões de brasileiros utilizaram a Internet em suas residências, contra 142,8 milhões de norte-americanos. O número de brasileiros que moram em domicílios equipados com computadores interligados à rede é de 21,2 milhões, quase a totalidade de moradores de áreas urbanas. O número de conexões Internet banda larga no país cresceu de 2,26 milhões em 2004 para 3,8 milhões em 2005, com projeções de 4,21 milhões em $2006^{5}$.

Figura 2. Acesso Mundo $-1^{\circ}$ trimestre $2006^{6}$



Para reduzir a info-exclusão, o governo tem como alvo dois públicos, separados por poder de compra. Um deles é formado pelas camadas D e E da população, compostas por famílias que ganham até três salários mínimos por mês. Para esse público, sem condição financeira de ter o próprio computador, o governo reserva espaços como os Telecentros, locais públicos onde a utilização de microcomputadores PCs com acesso à Internet é gratuita. Já entre as famílias que recebem de três a dez salários míni-

4 Disponível em: <http://www.itu.int/> e <http://www.teleco.com.br/uitdai.asp>. Acesso em: 27 mai. 2006.

5 Cf. <URL: http://www.teleco.com.br/comentario/com94.asp>, <URL http://www.teleco.com.br/ blarga.asp > e <URL: http://www1.folha.uol.com.br/folha/informatica/ult124u20243.shtml> com dados do Ibope/ NetRatings, Anatel e ABTA. Acesso em 25 mai. 2006.

6 Base: pessoas com dois anos ou mais que moram em domicílios com acesso à Internet via computador doméstico, em milhões. Fonte: GNETT - IBOPE/NetRatings. 
mos, $12 \%$ dependem de programas de financiamento popular para adquirir um computador PC. Para o segundo público alvo, o governo tem incentivado o "PC Conectado", parcialmente subsidiado, dentro da mesma idéia do medicamento genérico, com baixo custo, sem comprometer a qualidade do produto. Além disso, há a esperança de que o Fundo de Universalização dos Serviços de Telecomunicações do Governo Federal (FUST) seja utilizado em sua finalidade original, que é levar Internet aos colégios públicos. Das 184 mil escolas de todo o país, 19\% têm laboratórios de informática, mas até 2004 apenas 3\% estavam conectadas à Internet. Desde que o FUST foi criado, em 2001, os recursos têm sido usados especialmente para tapar buracos do orçamento (PEIXOTO, 2004).

A redução do fosso digital conta não apenas com o subsídio público, mas especialmente com a participação de organizações do setor privado e de ONGs, dentro de um "espírito cidadão" e de parcerias criativas. Nas iniciativas líderes do setor público e das ONGs, destacam-se projetos como o Casa Brasil (http: / www.inclusaodigital.gov.br/), o Cidadão Conectado (http: / / www.computadorparatodos.gov.br/), os Telecentros pela Inclusão Digital (TID) (http: / / www.tid.org.br), uma parceria entre as ONGs Rede de Informações para o Terceiro Setor (RITS) (http://www.rits.org.br) e Coletivo Digital (http: / www.coletivodigital.org.br), este ligado ao Projeto Telecentros BR da Petrobrás; também, o Comitê para a Democratização da Informática (CDI) (http://www.cdi.org.br). No âmbito estadual, alguns governos se tornaram referências internacionais em e-Gov, como é o caso da prefeitura e do governo de São Paulo (http:/ / www.prefeitura.sp.gov.br e http://www.sp.gov.br).

\section{Comunicação digital: promoção da e-democracia}

A inovação digital tem mudado os paradigmas comunicacionais quando segmenta, "desintermedeia" ou corta transversalmente as tradicionais relações da sociedade em diversas dimensões e facetas. A comunicação nesta nova configuração permite que todos os atores sejam emissores e receptores, num elevado nível de interatividade entre as partes e, em tese, com os mesmos graus de visibilidade e de oportunidade. A Internet, em especial, provocou expansão na forma pela qual as pessoas e organizações se relacionam, dada a sua rapidez, acessibilidade, transculturalidade e transnacionalidade. Ela alterou a noção do tempo e do espaço, o tipo de acesso aos bens e serviços, a relação entre a noção de cidadania e o universo da política. Até linguagem e cultura locais têm sofrido significativas transformações.

A presença e a importância das TICs nos órgãos governamentais contribuem para mudanças que propiciam o surgimento de um conceito funcional de sistema misto de "governo tradicional e governo eletrônico", com influências internas e externas na forma de ser do governo e na comunicação e interação com seus públicos. É este mix de ações de governo tradicional e eletrônico que propicia as bases e condições adequa- 
das para o desenvolvimento da cidadania, da política e da democracia virtuais, com a presença das TICs em todos os processos do governo, quer sejam eles internos - dentro da própria máquina - ou externos, na interação com seus públicos. Nesta direção, a democratização eletrônica é agente importante para tornar as informações governamentais e políticas mais transparentes e abundantes para os cidadãos.

Surgem, então, relações on-line dentro da esfera pública na forma de governo eletrônico (e-governo, e-gov ou governo on-line), o que representa a transformação dos moldes tradicionais de relacionamento, informações e prestação de serviços entre o governo, os cidadãos e as organizações. As organizações públicas têm no e-Gov uma estrutura organizacional mais matricial e interativa, que interliga setores, departamentos, serviços, bases de dados e sistemas de informações, numa convergência que cria condições de atender as expectativas dos cidadãos quanto às suas necessidades de informação, comunicação e de melhores serviços públicos. Os vetores que norteiam o e-gov estão circunscritos simultaneamente às seguintes dimensões essenciais na relação governo-cidadão:

- Plano informacional - o governo propicia aos cidadãos informações on-line com maior efetividade;

- Plano de serviços - o governo mostra-se mais acessível aos cidadãos por meio de um portifólio de serviços on-line;

- Plano comunicacional - o governo incrementa e melhora sua comunicação - direta, on-line e interativa - com os cidadãos e organizações, e vice-versa.

A amplitude do relacionamento digital on-line é tal que as limitações típicas das relações físicas, temporais e sincrônicas são superadas, cedendo lugar a ações que podem abranger localidades geográficas de escopo local até mundial, de serviços on-line simples até os mais complexos, de atendimentos de horário comercial expandidos até o paradigma da alta disponibilidade $24 \times 7 \times 365^{7}$.

Aplicações pragmáticas do relacionamento virtual dos governos com seus públicos estão, de forma intensa, com desenvolvimento acelerado nos últimos anos, e se destacam mais à medida que aumenta o avanço da presença e alcance das novas redes telemáticas. Nos EUA, por exemplo, o Council for Excellence in Government, do governo norte-americano, definiu objetivos centrados nos cidadãos e no processo democrático:

"Primeiramente, há o uso das tecnologias de comunicação e informação para melhorar a eficiência e efetividade das funções executivas do governo, incluindo a disponibilização de serviços públicos. Em segundo lugar, as TICs abrem novas possibilidades para os governos serem mais transparentes aos cidadãos e empresas, dando acesso a uma vas-

7 A convenção "alta disponibilidade" $(24 \times 7 \times 365)$ representa 24 horas por dia, 7 dias por semana e 365 dias por ano. 


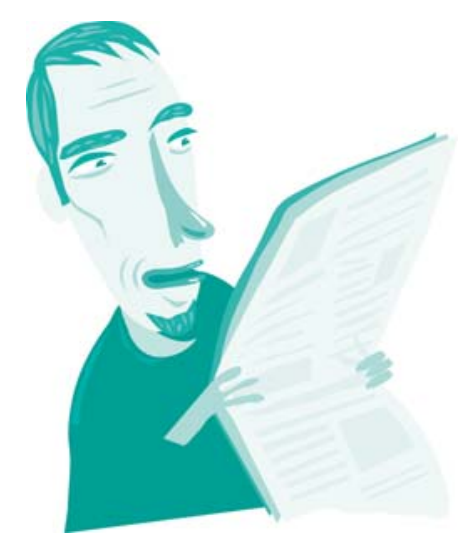

ta gama de informações controladas e geradas pelo próprio governo. Em terceiro lugar, a adequação do governo às TICs pode proporcionar mudanças fundamentais no relacionamento entre os cidadãos e o estado, e entre nações, com implicações para o processo democrático e as estruturas de governo. Em quarto lugar, a grande importância dos cidadãos na tomada de decisão no processo democrático." (EXCELGOV, 2004)

A atitude de propiciar mais informações e novos canais virtuais para os cidadãos por meio das novas TICs, sem intermediários burocratizantes ou filtros ideológicos, implica uma postura diferente das antigas práticas dos governos, acentuando o e-Gov como democrático, eficiente e com maior credibilidade. Informações oficiais e públicas com acesso irrestrito para os cidadãos são fundamentais para aperfeiçoar os processos de discussão pública e política na democracia, e para aumentar a confiança dos cidadãos em relação ao governo. Rheingold (1993) observa que a habilidade dos grupos de cidadãos em debaterem assuntos públicos é largamente aumentada pelo acesso amplo e instantâneo às informações sobre os fatos que poderiam sustentar ou rebater declarações feitas em tais debates.

Ambos, cidadãos e governos, estão aprendendo a tirar melhor proveito das facilidades da Internet, conforme apresentado no quadro 1, no qual são enumerados os principais serviços, com seus respectivos níveis de adoção pela população brasileira. O egov facilita sobremodo a distribuição de serviços governamentais com maior eficácia a partir da integração - ou clustering 8 - destes serviços, além de torná-los disponíveis por meio de um único ponto de acesso na Internet: uma simples janela transfigurada em um portal Web onde convergem endereços virtuais (hiperlinks) para uma infinidade de serviços essenciais, mais rápidos e melhor organizados em um só lugar, reduzindo custos, duplicações e retrabalhos.

Mesmo assim, especialmente no contexto dos países em desenvolvimento, muito do potencial oferecido pelas possibilidades do e-Gov ainda está por ser construído. As barreiras de acesso democrático, da língua dominante e da capacitação ao uso da tecnologia são desafiadoras. Há ainda a necessidade de uma estratégia pública para viabilizar e popularizar a assinatura digital, requisito essencial para tornar os serviços

8 A oferta de serviços de e-Gov em clustering é tida como a oferta de um portifólio integrado de serviços em um portal na Internet. 


\section{Quadro 1. Serviços de e-gov no Brasil utilizados na Internet*}

\begin{tabular}{|lc|}
\hline $\begin{array}{l}\text { Percentual sobre o total de usuários de serviços de } \\
\text { e-Gov }\end{array}$ & $\begin{array}{c}\text { Total } \\
\text { (\%) }\end{array}$ \\
\hline Consuta ao CPF - Cadastro de Pessoa Física & 50,48 \\
\hline Declaração de Imposto de Renda & 40,79 \\
\hline Inscrição em consursos públicos (Polícia Militar etc.) & 26,84 \\
\hline Informações sobre serviços públicos de educação & 21,82 \\
\hline Informações sobre emprego & 17,77 \\
\hline Pagamento de IPVA, multas, licenciamento & 17,15 \\
\hline Informações sobre serviços públicos de saúde & 11,20 \\
\hline Informações sobre direitos do trabalhador (Previdência etc.) & 10,65 \\
\hline Informações sobre como emitir documentos (RG, CPF etc.) & 9,28 \\
\hline Pagamento de taxas de serviços públicos (água, luz etc.) & 8,85 \\
\hline Obtenção de certidões negativas & 7,40 \\
\hline Informações sobre programas assistenciais (Bolsa-família etc.) & 6,66 \\
\hline Pagamento de IPTU e outro impostos & 5,28 \\
\hline Boletim de ocorrência & 2,76 \\
\hline * Base: 1.083 entrevistados que usaram Internet entre set/204 e set/2005. \\
\hline Respostas múltiplas (pesquisa realizada em ago-set/2005 - Instituto IPSOS).
\end{tabular}

públicos on-line mais amplos e confiáveis ${ }^{9}$. A iniciativa privada, por outro lado, caminha a passos largos na adoção dos novos media, serviços e comunicação on-line.

\section{Cibercidadão: a cidadania política ativa}

No regime democrático, a definição do papel do governo, dos partidos, candidatos e cidadãos num ambiente em rápidas transformações nem sempre é tarefa simples. A

9 O Instituto Nacional de Tecnologia da Informação (ITI) é a Autoridade Certificadora Brasileira Raiz - AC Raiz - da Infra-Estrutura de Chaves Públicas Brasileira - ICP-Brasil: <URL: http://iti.br/>. 
real participação cívica, social e política prevê a existência e a disponibilidade de canais de comunicação apropriados para tal, e requer o repensar das práticas estabelecidas, uma vez que a "desintermediação" nos canais de comunicação se torna uma realidade cada vez mais concreta. A conectividade interativa e global dos novos media propicia o aparecimento espontâneo de fenômenos que podem independer da intervenção de agentes governamentais ou políticos, em face de seu caráter democrático.

O jornalista Jonathan Katz, um dos escritores norte-americanos visionários da era digital, assim se expressou em 1997 sobre o surgimento do cibercidadão e a potencialidade de uma nova conversação social e política em rede ${ }^{10}$ :

"Na rede, no último ano [1996], eu vi o renascimento do gosto pela liberdade nos media. Eu vi a multidão repleta de pessoas inteligentes, educadas e politicamente apaixonadas, que - em contraste discordante do mundo offline - se dispunham a expressar suas opiniões cívicas, participar em debates e até lutar por seus ideais políticos. Eu observei as pessoas aprendendo novas maneiras de se comunicarem politicamente. Eu vi informações viajando por grandes distâncias e voltei para minha casa com a mente marcada pelas pessoas engajadas e mobilizadas em todos os lugares do mundo. Eu vi posições desanimadas mudarem, quando as pessoas de repente puderam ser capazes de conversar diretamente umas com as outras, sem a intermediação de jornalistas, políticos ou ideologias mercenárias.

Eu vi o surgimento inicial de um novo tipo de nação - a nação digital - e a formação de uma nova filosofia pós-política. Esta ideologia nascente, confusa e dificil de ser definida, sugere a combinação de alguns dos melhores valores resgatados dos dogmas antigos e enfadados - o humanismo do liberalismo, a oportunidade econômica do conservadorismo, mais um forte senso de responsabilidade e a paixão pela liberdade." (KATZ, 1997, p. 01)

Os cibercidadãos, atores políticos em potencial e hiperconectados, possuem a noção de que as comunicações interativas em rede (caso da Internet e dos celulares) podem influir nas relações de poder entre governantes e governados. O seu acesso à Internet se caracteriza como eficiente meio de expressão política. As comunidades virtuais crescem a altas taxas na Internet, transcendendo as barreiras do mundo físico. Perpassam as limitações dos outros meios de comunicação como TV, rádio, jornais e revistas. É muito simples a propagação de idéias e informações e os cibercidadãos caminham para um futuro em que cada indivíduo provavelmente terá o seu próprio espaço virtual ${ }^{11}$.

10 Tradução nossa. Tapscott (2000) trata pragmaticamente os conceitos da "geração digital".

11 Os WebBlogs (diários digitais pessoais na web), os Podcasts (áudios na web) e tecnologias similares estão crescendo em larga escala. A Web 2.0, a segunda geração da world wide web, é uma tendência que reforça o conceito de troca de informações e colaboração dos internautas com sites e serviços virtuais. A idéia é que o ambiente on-line se torne mais dinâmico e que os usuários colaborem para a organização de conteúdo. Incluem-se nesta definição o Mash-Ups, o AdSense, o RSS e os Wikis. 
Neste sentido caminham os partidos, candidatos e eleitores, que ganham maior visibilidade na Web e garantem suas contribuições pessoais à teia global.

Uma clara definição e descrição acerca do perfil psicológico típico do cibercidadão é apresentada por Jonathan Katz:

"Entendido, tolerante, com tendências cívicas e radicalmente propenso a mudanças. Profundamente otimistas sobre o futuro, eles são convictos que a tecnologia é um poder para o bem e que a economia de livre-mercado funciona como um poderoso instrumento de progresso. [...] Seus valores públicos revelaram que atualmente eles são altamente engajados e vêem positivamente e patrioticamente nosso sistema político existente". (KATZ, 2000, p. 02)

O governo e os organismos políticos que sempre regularam os estímulos aos cidadãos e à sociedade estão diante de novas circunstâncias e seu incentivo à participação e manifestações democráticas surge mais naturalmente a partir dos próprios cidadãos, de grupos organizados e das ONGs. Como agente incentivador, caso não assuma proativamente o seu papel, o governo estará sujeito a ficar gradativamente mais passivo nesses novos contextos. A atuação popular na política é resultado direto da percepção do cidadão, fruto de seu amadurecimento na vida democrática e de como está estruturado a estrutura social, pública e política.

\section{Ciberdemocracia: um novo espaço público}

Na visão de Leo Scheer, o cidadão só é reconhecido na sociedade à medida que participa da sua história, que possua interesse e relação com a política e com os que de-

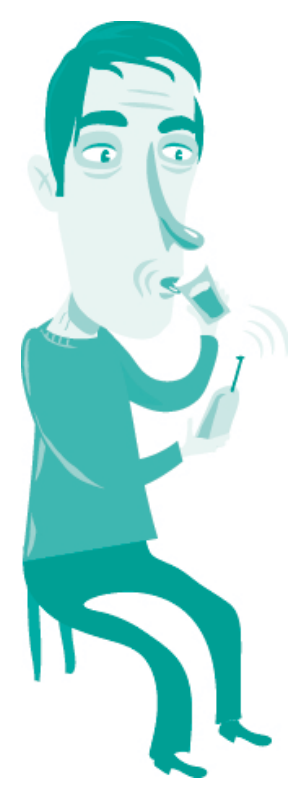


la falam, com orientação para um destino comum. No exercício da cidadania é essencial que os cidadãos sejam coadjuvantes e que suas intervenções tenham efeitos concretos (SCHEER, 1997).

Nesse sentido, a "praça" pública, ainda representada preponderantemente pela TV e mídias offline, começou a ceder espaço e atenção para os media digitais interativos ${ }^{12}$. A globalização, assim como seus blocos políticos e mercadológicos, tem suscitado a percepção e a necessidade dos governos em construírem os fundamentos que sustentam a sociedade atual nesse novo contexto. No que se relaciona ao processo de emancipação humana, Pierre Lévy defende que "a capacidade de comunicar e de circular tem estreita relação como o desenvolvimento da liberdade”. Ele reforça:

"Estaríamos propositadamente a cegar-nos se imaginássemos que não há evoluções técnicas e culturais ainda mais importantes e surpreendentes do que as que conhecemos $\dot{a}$ nossa espera no futuro [...] Mais comunicação implicará mais liberdade. No século que começa, não é somente o ciberespaço que irá crescer, será também a ciberdemocracia". (LEVY, 2002, p. 23)

Entre os representantes políticos e os cidadãos, a facilidade propiciada pela comunicação em rede possui extremo potencial de impacto no contexto de governo eletrônico. Se a TV já mudou as regras de Comunicação Política, mesmo com a alusão às suas barreiras - altos custos, acesso massificado e falta de interação - as novas tecnologias digitais interativas se apresentam como instrumentos estratégicos para a comunicação mais democrática de dupla-mão entre cidadãos e políticos, e entre cidadãos e governos. Os novos canais facilitam e estreitam tais relações de formas antes impossíveis, com os cidadãos tendo acesso virtual direto aos seus representantes governamentais.

\section{A ética e a construção da confiança on-line}

Apesar de todas as vantagens e potenciais pertinentes às novas tecnologias para o governo, a política e a sociedade, existem pontos ainda não equacionados. Entre eles estão questões éticas como o controle e a regulamentação, a confidencialidade, a privacidade, a idoneidade e a transparência.

A popularização das TICs de forma não-excludente e com abrangência irrestrita permitirá maior aproximação do ideal democrático do acesso às informações e conhecimentos universais, com transparência, solidariedade, direitos humanos e participação dos cidadãos. Por outro lado, caso não se observe tais premissas democráticas, as

12 A iTV, ou TV digital interativa, por exemplo, é uma sinergia dos recursos de ambas as tecnologias, Internet e TV. 
TICs podem se tornar novos instrumentos para hegemonias antidemocráticas e elitizadas, aumentando as desigualdades econômicas e sociais, em detrimento dos já excluídos pelos poderes locais, regionais, federais e multinacionais.

Por serem globais e cada vez mais pervasivamente onipresentes, as regras ou legislações locais não são tão eficazes como em outros meios de comunicação. A fonte, ou emissor, pode ser migrada com facilidade para qualquer local do planeta, o mesmo podendo ocorrer com o receptor.

No governo, na política ou na sociedade, as tentativas de regulamentar as atividades na Internet - como o hackerismo ${ }^{13}$ - são de difícil controle. Aliás, a sua desregulamentação é tida como um de seus pontos fortes, como meio livre e democrático, aberto à manifestação de todos, para quaisquer mensagens.

Um documentário político veiculado na época da disputa presidencial brasileira de 2002 mostrou o choque das novas forças midiáticas fazendo contraponto com o tradicional cerceamento de opinião de regimes ainda totalitários ou numa fase mais incipiente da prática da democracia:

"Na Ucrânia, Georgy Gongadze havia escrito artigos na Internet criticando Leonid Kuchma, o presidente ucraniano. O corpo decapitado de Gongadze foi encontrado em um bosque, meses depois de ele ter desaparecido: 'o que está havendo é a liderança comunista da velha guarda entrando em choque com novas forças, como a Internet, como a televisão moderna, a mídia moderna"”. (DESTAQUES EM POLÍTICA, 2002)

O Centro para a Democracia e Tecnologia dos EUA (CDT), por exemplo, surgiu em defesa da não regulamentação da comunicação e atividades políticas na Internet, e do incentivo aos cidadãos acerca do processo democrático por meio da Web, com influência no próprio Federal Election Commission (FEC), órgão eleitoral federal americano (LANVIN, 2002). A mensagem abaixo sintetiza a missão do CDT:

"A Internet está estimulando uma explosão de atividade democrática fora do controle dos partidos políticos, da mídia tradicional ou de ostentosos interesses especiais. $\mathrm{Na}$ Internet pode ser encontrada definitivamente toda espécie de apoio político individual que as leis de financiamento de campanhas pretenderam promover [...] e porque ela deveria ser deixada de forma desregulamentada". (CDT, 2000, p. 01)

A garantia de privacidade do cidadão ou eleitor está na pertinência de que seus dados pessoais não estejam acessíveis de forma não autorizada a terceiros ou a outras ins-

13 Refere-se a especialistas ou pessoas habilidosas em programação, administração de sistemas computacionais e segurança eletrônica. 
tâncias das próprias organizações e governos. Na Internet, toda transação ou processo é registrado na cadeia por onde circula a informação, ou seja, sempre há rastros digitais deixados pelo usuário com conseqüente possibilidade de vigilância da sua liberdade de pensar e de se comunicar. Os rastros podem se tornar instrumento das organizações contra o próprio cidadão, e facilitando a formação de monopólios dos detentores da informação ${ }^{14}$. Tal como no mundo físico, ou, como já ocorre com o comércio eletrônico, uma relação de confiança mútua deve ser construída por meio de relacionamentos mais estreitos entre os agentes, cidadãos, consumidores ou usuários e as organizações envolvidas ${ }^{15}$.

\section{Considerações finais}

Os governos e as instituições públicas estão se reinventando quando incorporam a grande rede e as telecomunicações em seus processos sociais e político-eleitorais. Se os paradigmas do "ter e possuir" da sociedade industrial mudaram para o "saber e conhecer" com o advento da sociedade em rede e das novas tecnologias digitais, então o ponto focal muda para como tirar proveito dessa riqueza que se apresenta para o governo, para a cidadania e para a democracia. A sociedade de informação continuará avançando em praticamente todas as facetas da sociedade e das organizações, independentemente dos retardatários, sejam eles países, governos ou instituições políticas.

A eficácia da Comunicação Pública na economia digital globalizada requer avanço estratégico do país na direção de como a sociedade, o governo e demais instituições tenham o pleno domínio das novas tecnologias, de sua infra-estrutura, seus conteúdos e seus usos. À medida que as características da nova economia vão se estabelecendo, a velha economia e seus tradicionais sustentáculos vão se esvaindo nas organizações e nos governos e na sociedade.

O governo brasileiro está diante de enorme desafio para o qual tem grande potencial: ampliar o relacionamento entre governo e cidadãos visando à promoção da cidadania por meio da inclusão social. A revolução tecnológica da informação evidencia uma crescente transformação da clássica democracia representativa para os moldes da democracia eletrônica na qual a comunicação é de dupla-mão, mais transparente e interativa.

14 A rede de inteligência Echelon dos EUA. Disponível em: <http://en.wikipedia.org/wiki/ ECHELON $>$.

15 Cf. Projeto UK Citizens Online Democracy. 


\section{Bibliografia}

BRITO, José Augusto P. O Contexto das tecnologias emergentes nos processos político-eleitorais: a democracia é possível? Tese (Doutorado em Ciências da Comunicação) - Departamento de Relações Públicas, Propaganda e Turismo da Escola de Comunicações e Artes. São Paulo: Universidade de São Paulo, 2005.

CASTELLS, Manuel. A era da informação: economia, sociedade e cultura. A sociedade em rede. São Paulo: Paz e Terra, 2000. (Volume I).

CDT. Center for democracy and technology. Disponível em: <http://www.cdt.org/speech/political/000107fec.shtml> . Acesso em: 24 jun. 2006.

CHAHIN, Ali. (et al.). e-gov.br: a próxima revolução brasileira: eficiência, qualidade e democracia - o governo eletrônico no Brasil e no mundo. São Paulo: Prentice Hall, 2004.

DESTAQUES EM POLÍTICA, Canal GNT. São Paulo: Rede Globo, 05 de out. 2002. (Programa de TV).

EISENBERG, José; CEPIK, Marco (org.). Internet e política: teoria e prática da democracia eletrônica. Belo Horizonte: Editora UFMG, 2002.

EXCELGOV. The council for excellence in government. 2004. Disponível em: <http://www.excelgov.org/> . Acesso em: 14 mai. 2006.

GENTILI, Pablo (org.). Globalização excludente: desigualdade, exc/usão e democracia na nova ordem mundial. Petrópolis: Vozes, 1999.

GOMES, Wilson. Transformações da política na era da comunicação de massa. São Paulo: Paulus, 2004.

KATZ, Jon. Birth of a digital nation. Wired Magazine. Issue 5.04, Apr 1997. Disponível em: < http://www.wired.com/wired/5.04/netizen.html>. Acesso em: 23 mai. 2006.

LANVIN, Bruno. The e-government handbook for developing countries. InfoDev and The Center for Democracy \& Technology - CDT. The World Bank. Nov. 2002. Disponível em: <http://www.cdt.org/egov/handbook/>. Acesso em: 21 mai. 2006.

LEVY, Pierre. Ciberdemocracia. Lisboa: Instituto Piaget, 2002.

LOCKE, Christopher (et al.). O manifesto da economia digital. Rio de Janeiro: Campus, 2000.

MATOS, Heloiza. Comunicação pública, democracia e cidadania. In: BRANDÃO, Beth; MARTINS, Luiz; MATOS, Heloiza (org.). Algumas abordagens em comunicação pública. Ano I, vol I, nº 3. Brasília: Casa das Musas, 2003. (Coleção Textos em Comunicação).

MCT-PT. Livro verde para a sociedade da informação em Portugal. Lisboa, 1997. Disponível em: <http://www.posconhecimento.pcm.gov.pt/documentos/pdf/ LivroVerde.pdf>. Acesso em: 14 mai. 2006.

PEIXOTO, F. O desafio da inclusão. Revista Época Negócios, ed. 344. 20 dez. 2004.

RHEINGOLD, Howard. The virtual community. Massachussetts: Addison-Wesley Publishing Company, 1993. 
CIBERCIDAdANIA: A VIRTUALIZAÇÃO NA COMUNICAÇÃO PÚBLICA CONTEMPORÂNEA • JOSÉ AUGUSTO PEREIRA BRITO

RUBIM, Antonio Albino Canelas. Comunicação \& política. São Paulo: Hacker Editores, 2000.

SCHEER, Léo. A democracia virtual. Lisboa: Edições Século XXI Ltda, 1997.

SILVEIRA, S. A. Exclusão digital: a miséria na era da informação. São Paulo: Fundação Perseu Abramo, 2001.

TAKAHASHI, Tadao (org). Sociedade da informação no Brasil - Livro Verde. Brasília: Ministério da Ciência e Tecnologia, 2000. Disponível em: <http://www.mct.gov.br/index.php/content/view/18878.html>. Acesso em: 03 mai. 2006.

TAPSCOTT, Don; CASTON, Art. Geração digital. São Paulo: Makron Books, 2000.

TORQUATO, Gaudêncio. Tratado de comunicação organizacional e política. São Paulo: Pioneira Thomson Learning, 2002.

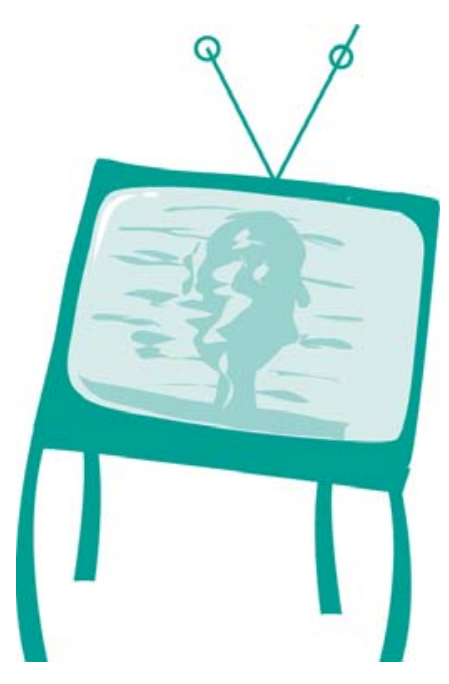

ANO $3 \cdot$ NÚMERO $4 \cdot 1^{\circ}$ SEMESTRE DE $2006 \cdot$ organicom • 123 